\title{
Manufatura Integrada por Computador e Organização do Trabalho
}

\section{Adriano Proença}

Doutorando do Programa de Engenharia de Produção da COPPE/UFRJ

palavras-chave: Gerência da produção, Manufatura integrada por computador, Organização do trabalho, Economia industrial

Key words: Manufacturing management, Computer Integrated manufacturing, Work organization, Industrial economy

\section{RESUMO:}

Este artigo tem por objetivo analisar a economia da fábrica automatizada para, a partir daí, delinear um modelo coerente de organização do trabalho. A questão é situada sob o enfoque estratégico, e destaca-se a necessidade de um novo método de projeto da organização do trabalho para essas fábricas.

\section{ABSTRACT:}

This paper presents the automated plant economics analysis and a model of work organization consistent with the characteristics pointed by the analysis. The questions are treated under the strategic approach and the conclusions point out to a new method of work conditions design for these companies.

Rec. 11/90 Rev. 12/90 Apr. 01/91 


\section{A Economia da Planta Automatizada}

O ponto de partida de nossa discussão é a alteração propiciada pela automação microeletrônica no comportamento do fenômeno conhecido como "economia de escala".

A definição clássica de economia de escala parte da modelação microeconômica tradicional (cf. Bibliográfica[8]). Tomando um gráfico de isoquantas crescentes de produção (quantidade de output: Q1,Q2,...) para um determinado mix de fatores (inputs) $\mathrm{X} \mathrm{e} \mathrm{Y}$, e superpondo às esoquantas curvas de custo, podemos observar que existem pontos ótimos de relação custo/quantidade, que geram uma função $C=f(Q)$. A partir desta, pode-se construir uma "curva de custo médio", na forma $\mathrm{C} / \mathrm{Q}=\mathrm{f}(\mathrm{Q}) / \mathrm{Q}$. Esta é a "curva de custo médio no longo prazo", que relaciona o custo médio de produção ao nível de output por unidade de tempo, assumindo que a firma procura minimizar custos. Observe-se que a firma escolhe para cada output a "técnica ótima", dados os preços dos inputs: não há restrições na escolha. A pergunta central no estudo do fenômeno da economia de escala é, justamente, se a função de custo médio no longo prazo mostra alguma tendência sistemática de diminuição à medida que aumenta a escala de operação. Quanto à "curva de custo médio no curto prazo", espera-se que ela tenha sempre a forma de um " $U$ ", na medida que existem custos fixos e outros variáveis. Para evitar confusões desnecessárias, destacamos que a escala de produção $(Q)$ não é sinônimo de tamanho de planta -- mensurável pelo número de máquinas, pessoas, área ocupada, etc.

Entre outras distinções, a literatura $[8,11]$ reconhece três níveis de economia de escala -- ao nível da firma, da planta e do produto. $\mathrm{O}$ produto se refere à firma como um todo, $\mathrm{e}$ envolve efeitos de operações multi-planta, diluição de gastos indiretos como P \& D e marketing, e vantagens pecuniárias -- redução de custo unitário por aquisição de grandes quantidades -- e financeiras -- acesso privilegiado a capital. A segunda trata da diluição dos custos associados à taxa mensal de produção, e a terceira da diluição de custos ao longo de toda a vida do produto. Interessamnos, aqui, as duas últimas formas.

Um estudo de Bela Gold [apud 15] já apontava, no início da década de 80 , uma série de problemas no conceito de economia de escala. Embora elegante (e adequada) para uma reflexão macroeconômica, a formulação tradicional não refletia a realidade micro. Não se poderia aceitar, por exemplo, que a gerência, ao aumentar a escala de sua planta, mantivesse constantes todas as proporções entre "inputs". Em outras palavras, que a escala aumentasse sem alteração na tecnologia de produção, ou mesmo na de produto. Gold observava que os benefícios práticos da elevação da escala derivavam de uma série de decisões da gerência, tais como maior especialização das linhas e das atividades de suporte, ou a implantação de sistemas de controle de materiais, estoques e qualidade. E que, na verdade, a introdução de tais aperfeiçoamentos não estaria necessariamente ligada a plantas maiores.

Esta reflexão de Gold chama nossa atenção para o fato de que, mesmo sem considerar a automação microeletrônica, é possível adotar soluções que proporcionam ganhos no rendimento do trabalho, independentemente de um maior tamanho da planta ou aumento da escala de produção. Não se deve, portanto, imaginar que só com novos equipamentos é possivel contornar a lógica da economia de escala. Neste texto, entretanto, nos ateremos a este tema em particular.

Retornando a Wood [15], os autores observam que a experiência comum e estudos de caso pareceram confirmar que, de fato, as economias de escala estariam associadas a 
plantas maiores. A explicação que dão para o fenômeno se apóia no fato de que a planta grande permitiria a adoção de soluções de redução de custo associadas à lógica do modelo de "linha de montagem", conforme formulado por Ford. Segundo Drucker [6], Ford concebeu a "linha de montagem" como uma solução de organização da produção capaz de sustentar uma estratégia de mercado de massas. Isto é, a organização em linha permitiria uma redução no custo unitário de produção que viabilizaria um preço baixo o suficiente para alargar de forma significativa o consumo de produtos. $\mathrm{O}$ saldo do processo seria muito positivo para a firma, aumentando seus lucros. A economia da planta fordista pressupõe, assim, uma elasticidade-preço na demanda, de modo a que quanto mais se produza e mais barato o produto fique, igualmente mais se venda. Esta perspectiva também está presente no pensamento econômico de Taylor [4].

As reduções de custo associadas à "linha de montagem" teriam como fonte, entre outras, as relacionadas a seguir $[4,7,15]$ :

- maior padronização do trabalho, dos insumos e das máquinas, permitindo uma intensificação do trabalho pela cadência imposta pela esteira;

- redução do tempo dedicado à preparação de máquina;

- redução dos custos indiretos de supervisão e atividades de suporte;

- melhor posição de barganha para a gerência na definição dos salários;

- eliminação de boa parte do contingente de trabalhadores encarregados do transporte de componentes e peças;

- aparecimento de "curvas de aprendizado" levando à redução de custos;
- giro mais rápido dos materiais;

- adoção de máquinas especializadas de produção.

Esta última solução de redução de custo associada à linha de montagem nos interessa em particular. O ganho de produtividade oriundo da especialização das máquinas - isto é, a capacidade da máquina especialista de produzir mais produtos com menos perdas, em menos tempo, a menor custo que a máquina universal - sempre pesou na decisão de aumentar a escala. Adquirir e ocupar este capital-fixo de modo que ele não fique ocioso exige volume de produção mensal: escala ao nível da planta. Além disso, há necessidade de longos ciclos de produção para diluir os elevados custos fixos iniciais desta automação rígida: escala ao nível do produto.

Com a automação microeletrônica, a situação se altera. A comunicabilidade proporcionada pela identidade informática dos equipamentos permite uma maior integração e coordenação do sistema produtivo, conduzindo a um uso mais intenso do capital-fixo, e, portanto, a uma maior produtividade por máquina. Permite também um melhor aproveitamento do capital-circulante, seja reduzindo seu tempo na planta, seja por operar com menores perdas de material, podendo também levar a uma intensificação do trabalho direto manual anexo à operação automática, caso este esteja presente no sistema. A programabilidade das máquinas, por sua vez, permite uma grande redução nos tempos de preparação de máquina, após uma fase inicial de aprendizado e estabilização dos softwares. Também por este motivo é possivel um uso mais intenso da maquinaria, aumentando sua eficiência. Note-se ainda que a redução do tempo de preparação permite uma redução no tamanho dos lotes, possilitando um ajuste mais fino na relação tamanho de planta/escala de produção. Temos assim uma redução 
no tamanho de planta necessário a um dado volume de produçáo mensal. Há, portanto, uma "compactação" da plantal.

Este primeiro aspecto da automação microeletrônica não conduz, entretanto, à redução na escala necessária para produção econômica (competitiva) de um determinado produto. Pelo contrário, Coriat [3] observa que os custos médios de produção iniciais da automação microeletrônica são hoje muito elevados, dados os custos de aquisição (todos os custos fixos iniciais, incluindo treinamento) e de manutenção dos equipamentos, e o fato de substituirem pessoal pouco qualificado, não significando economia significativa nesta área. Colocada a necessidade de diluir tais gastos, a automação microeletrônica aparece como vantajosa por reduzir os custos associados ao alongamento dos ciclos de produção (operações à noite, nos fins de semana).

Há, entretanto, quem preveja uma queda futura nos custos das atividades de suporte da planta, o que facilitaria uma redução nas escalas mínimas de produção. Talaysun et alü [15] observam que o advento de sistemas especialistas (experts systems) permitiria uma redução significativa nos overheads de aperfeiçoamento do planejamento e controle da produção, do sistema de qualidade, da engenharia mecânica $e$ industrial, etc. Isto porque, após sua confecção, o custo do sistema ser operado e reproduzido é bem pequeno. Portanto, o progresso da informática -- hardware e software -- poderia levar a uma dramática redução dos custos indiretos de produção.
Há também resultados de campo apontando para uma associação "automação microeletrônica <=> simplificaçåodasorganizaçðes". Jaikumar [apud 9] relata que fábricas automatizadas podem alcançar redução de uma ordem de magnitude expressiva no número de pessoas de suporte e no de trabalhadores indiretos requerido para uma certa produção, além de eliminar vários níveis gerenciais.

A (re)programabilidade da maquinaria propiciada pela automação microeletrônica conduz, entretanto, a outras formas de economia na planta. Essencialmente, torna-se viável o funcionamento flexível da planta automatizada; isto é, ela pode operar com lotes menores - pois o tempo de preparação de máquina é pequeno - de produtos variados. Economias geradas por esta capacidade são definidas como "economias de escopo", por estarem associadas à variedade de produtos. Não nos deteremos, neste artigo, na discussão deste conceito.

Esta característica permite, em primeiro lugar, que se ocupe o capital-fixo instalado via variedade de produtos. Isto é, produtos que não poderiam ser produzidos em "grande" escala por ausência de mercado, mas que necessitariam ser produzidos a "baixo" custo para poderem ser lucrativamente vendidos, podem ser fabricados em uma mesma planta flexível, de tal forma que os custos diretos fixos (e os custos fixos iniciais) sejam distribuídos por todos. Note-se que a produção na planta flexível não gera necessariamente um produto de menor custo que $o$ da planta rígida; o mercado, que é limitado, inviabiliza esta última, e, ao mesmo tempo, aceita um preço maior

\footnotetext{
'Mas em plantas näo muito pequenas, Kaphnski observa que em relação à produção discreta em lotes pequenas ou unitários -- $O$ clássico job shop -- aumenta a escala mínima de produçâo. Isto porque näo só as equipamentos microeletrônicos exigem maior investimento (crescem os custos fixos iniciais, e também os custos diretos fixos, exigindo escala ao nível do produto e da planta), como também porque parecem funcionar melhor com a intraduçäo de tecnologia de grupo (que reforça a presença de economias de escala ao nivel de produto).
} 
pelo produto fabricado na primeira. Observese ainda que para obter esta forma de economia de escala não bastam equipamentos programáveis; é preciso que os produtos operem com outros insumos semelhantes força de trabalho, materiais - para que se opere eficientemente com um largo escopo de produção.

O papel do comportamento do mercado consumidor na compreensão da lógica da economia da planta automatizada se explicita ainda mais se avançarmos em direção a um segundo potencial desta nova base técnica: a capacidade da planta "colar" na demanda, se adaptando às mutações no comportamento desta, seja:

- alterando o mix de produção;

- alterando seus produtos;

- lançando novos produtos, se adiantando ao movimento dos consumidores.

A ligação com o mercado, também facilitada por outras inovações associadas à base técnica microeletrônica (telemática), evita desperdícios de recursos com produtos que não venderão.

A possibilidade de alteração na linha de produtos produzida pela planta se explica, para produtos semelhantes (apenas diferenciados), pela polivalência das máquinas e pelo baixo custo de alteração de softwares já desenvolvidos. Para o caso de lançamento de novos produtos, tem-se a possibilidade de reutilização dos equipamentos adquiridos para estes novos fins, de forma que, para esta nova geração de produtos, os custos fixos iniciais seriam menores. Teríamos aqui uma economia de escopo ao nível do produto. Observese que, novamente, é a expectativa quanto ao comportamento do mercado que irá definir se o melhor é continuar a diluir os custos fixos iniciais na geração passada, ou se é mais interessante lançar a nova por um preço maior.
O custo desta nova geração será menor para a planta que reutilizar investimentos parcialmente já pagos, pois novos entrantes sairiam do zero; mas, ceteris paribus, é evidente que não há como o novo não sair mais caro que $o$ antigo.

Finalmente, cabe destacar as características da curva de aprendizado na economia da planta automatizada. A literatura reconhece apenas dois tipos de "economias de aprendizado" - talvez porque são os que se consiga verificar com um mínimo de clareza. Teríamos a redução de custo oriunda do aprendizado de habilidades manuais por parte dos trabalhadores diretos e a originada de melhorias na produção, devidas à aplicação do conhecimento de operários, técnicos e engenheiros, que encontrariam, ao longo do tempo, formas mais fáceis de fazer as coisas. Entretanto, chamaríamos ainda a atenção para outras mudanças que ocorrem no tempo: evolução da própria organização do trabalho; um aprendizado geral quanto ao comportamento do grupo, com a formação de uma cultura fabril mais homogênea a orientar a tomada de decisões; e outros elementos intangíveis que acabam por ter efeitos na redução do custo unitário médio dos produtos.

No caso da planta automatizada, a ausência de grande volume de intervenções manuais de produção conduz a outras formas de aprendizado. A variedade de produtos e a necessidade (mercadológica) de sua permanente evolução deslocam para a própria planta, enquanto organização, a responsabilidade de promover a queda dos custos de produção. Enquanto antes a perspectiva era de um aprendizado associado ao volume de produção de um dado produto, agora têmse vários produtos com menores ciclos de vida, com o aprendizado de um sendo transferido para o outro.

A própria base técnica microeletrônica permite acelerar um processo coletivo de apren- 
dizado. A informatização dos circuitos de comunicação pode auxiliar a coordenação entre as várias atividades, facilitando um esforço gerencial de melhorar o desempenho global da firma. Por exemplo, a integração da engenharia de produto com a de processos conduz ao projeto de produtos mais manufaturáveis que, desde o início de sua vida, já são produziveis a baixo custo [1,3]. Aliás, a ênfase japonesa para o conceito de CIM (Manufatura Integrada por Computador) é a integração Produção $<=>$ P \& D $\Leftrightarrow=>$ Marketing, e não a integração da planta em si. Estamos falando, portanto, de buscar uma "produtividade sistêmica" [17], e não local. Fica claro que a planta só faz sentido enquanto parte do sistema de negócio da firma; embora isto tenha sido sempre verdade, a automação microeletrônica torna-o evidente.

\section{Transformações na Organização do Trabalho}

O modelo clássico de organização do trabalho é a conhecida proposta de F.W. Taylor de uma "administração científica". Ao nível da gerência do trabalho direto, o cerne da proposta de Taylor é a elevação do rendimento do trabalho individual, a partir da análise e reconstrução da tarefa a ser executada na forma do melhor método imaginado para realizá-la. Este estudo, feito pela gerência, permitiria uma organização racional do trabalho na planta, conduzindo a uma intensificação e a uma maior produtividade do mesmo. $O$ controle da gerência sobre o trabalhador, possibilitado pelo seu conhecimento sobre as tarefas, se faria acompanhar de premiações para os melhores desempenhos. Este mesmo conhecimento permitiria à gerência selecionar e treinar os novos trabalhadores, recrutando-os mesmo entre aqueles que jamais tivessem adentrado os portōes de uma fábrica. Ao nivel da estrutura da organização, Taylor propôs uma divisão funcional do trabalho de suporte, que evoluiu para o desenho em linha-staff na maior parte das plantas. Este arranjo permite, a princípio, a concentração de competências de mesma especialidade, ao mesmo tempo que guarda linhas de autoridade bem definidas.

A "linha de montagem" de Ford, cujas vantagens, como vimos, costumam servir a explicaçōes para as economias de escala na produção discreta, aprofunda a idéia de gerência heterônoma, ao delegar à esteira a gestão dos fluxos de materiais e a imposição das cadências de trabalho.

A discussão relacionada à maneira que tais propostas foram aplicadas dentro e fora de seu país de origem (EUA) não têm lugar aqui. Queremos apenas ressaltar a sua natureza rígida, onde o trabalho é sistematicamente projetado, prescrito e controlado.

Ora, o que a análise da economia da planta automatizada revela é que, no tocante à organização do trabalho, é preciso pensar formas de:

- garantir o real aproveitamento da possibilidade de integrar e coordenar o uso das máquinas e dos materiais;

- reduzir o custo da implantação e das atividades de manutenção dos sistemas;

- alterar o mix de produtos, os produtos, e lançar novos produtos, de forma eficiente $e$ eficaz, quando o mercado assim o pedir; capacidade de aceitar a turbulência no mercado;

- precipitar um intenso esforço de aprendizado, individual e coletivo, que torne a organização mais ágil e produtiva que a concorrência.

Tais objetivos não são compativeis com o modelo clássico de organização do trabalho. Não é só a redução do volume de trabalho manual que está em jogo aqui; é a própria 
lógica econômica da planta que se altera. Para a organização do trabalho, o essencial passa a ser:

1) o progresso do conhecimento na planta; $e$

2) a coordenação entre as diversas atividades na planta.

Sobre o primeiro aspecto, Adler [1] chama atenção para a importância da "gerência do conhecimento" (knowledge management), espinha dorsal da gestão do trabalho em sistemas automatizados. Ele admite a ausência de modelos para esta atividade, mas destaca que é preciso pensar como fazê-la, isto é, como dinamizar a utilização dos conhecimentos atuais e a aquisição de novos saberes, tendo em vista as estratégias adotadas pela firma. Entendemos que é preciso uma "estratégia de aprendizado" que facilite a implantação de equipamentos e a melhoria das operações cotidianas.

Quanto à ação coletiva, Veltz [17] destaca, entre outros, a paralelização gente/equipamentos (equipes cada vez maiores para sistemas cada vez mais integrados) e a concomitante necessidade de se pensar as formas de cooperação e coordenação das pessoas para que dados se transformem em conhecimentos; ou seja, há necessidade de pensar uma maneira de organizar o "sistema cognitivo global" da firma (o termo é de Veltz). Ou seja, o que se busca é uma estrutura que organize e dinamize o trabalhador intelectual coletivo atuante.

Esta estrutura poderia ser calcada no que Butera (apud [2]; cf. [13]) chamou de "modelo orgânico"' de organização, em contraposição ao "modelo mecânico" da abordagem tradicional. O modelo orgânico teria quatro aspectos fundamentais:

- a organização é entendida como uma rede de sistemas auto-regulados;
- os papéis profissionais são baseados em uma mínima especificação crítica;

- os recursos humanos são entendidos como componentes do sistema; e

- a cultura predominante é de interação e solução de problemas.

Coerentemente, os princípios de projeto associados incluiriam, entre outros:

- admitir a natureza composta das firmas, com unidades autônomas, auto-reguladas;

- estabelecer ligações baseadas em troca de informaçð̃es entre os nós da rede;

- centralizar o controle estratégico e descentralizar o controle operacional;

- entender a manutenção e a inovação como tarefas de linha;

- estabelecer especificações mínimas de estruturas, cargos e procedimentos; etc.

O objetivo do modelo orgânico é potencializar o uso da inteligência da organização, de modo a acelerar o vetor de progresso da planta ao mesmo tempo que a deixa mais ágil para reagir ao ambiente, dado como turbulento. Pode funcionar, portanto, como a estrutura mais eficaz para sustento de uma estratégia de aprendizado. Ainda não estão claros quais os métodos para projetar um arranjo organizacional segundo esta orientação; mas acreditamos que é preciso caminhar nesta direção.

\section{Conclusão}

Uma planta automatizada não deve ser projetada sem que se considere sua inserção em uma estrutura de CIM. Entendemos que o objetivo estratégico de um investimento em 
direção ao CIM é a capacitação da firma em responder rapidamente, a custos aceitáveis, às turbulências no mercado consumidor. A firma pretende ou reagir à concorrência que está agredindo o mercado com uma oferta variada de produtos, ou quer ela mesma atingir o mercado com uma renovada capacidade de ação. Para a gerência da planta, esta estratégia de negócio se converte então em um dado: o mercado se tornou "demandante" de flexibilidade, porque não aceita mais produtos padronizados. Passa-se então a procurar a solução mais eficiente (ou menos ineficiente) para esta situação.

Em alguns casos, esta solução pode ser trabalho-intensivo. Mas, em sua maioria, as plantas só terão ganhos reais de produtividade com investimentos em capital fixo [9]. Cabe à gerência da planta, então, estabelecer uma estratégia de produção (cf. [12]) que prescreva qual a configuração-objetivo de equipamentos, e onde e quando serão introduzidos. Tal solução deve considerar a relação informática e operacional entre a planta e as outras atividades da firma (p. ex., marketing, compras): ela deve se inserir no modelo global de CIM da firma.

A formulação da estratégia de produção inclui ainda diversos outros aspectos da produção, tais como planejamento e controle da produção, qualidade, etc., e deve levar em conta restrições relativas ao mercado fornecedor de insumos materiais e de serviços; ao mercado de trabalho em todos os níveis; e as perspectivas quanto ao mercado de capitais e a economia geral circundante à firma. Condicionantes e soluções particulares devem ser pensados de forma integrada. Por exemplo, o projeto dos sistemas de hardware/software da planta não pode ignorar que serão pessoas que irāo utilizá-lo, e a expectativa quanto a quem serão tais pessoas depende de avaliações de mercado de trabalho e dos perfis profissionais e sócio-culturais da população trabalhadora disponivel.
Para nós, interessa justamente ressaltar aqui a importância crucial dos princípios subjacentes ao projeto de organização do trabalho na formulação da estratégia de produção. Como vimos, a planta automatizada exige uma reformulação das prescrições tradicionais para o projeto de organização do trabalho. A idéia de um "modelo orgânico" articulado a uma "gerência do conhecimento" está bastante distante de uma organização hierárquica cujo objetivo é garantir o máximo rendimento do trabalho direto. $\mathrm{O}$ que Drucker [6] chama de "gerência do trabalhador intelectual" saiu do campo das atividades de suporte e de P \& D, e parece já hoje atingir toda a planta.

De fato, Hayes e Wheelwright [9] e Adler [1] fazem do aprendizado a questão-chave da manufatura contemporânea. Wood [18], por sinal, identifica no kaizen japonês a filosofia de permanente melhoria, o coração do modelo japonês de organização da produção. Todas as propostas de solução técnica a ele associadas - jit, tqc, círculos de qualidade, etc - deveriam ser entendidas principalmente como meios de praticar//forçar o aprendizado contínuo.

Uma estratégia de produção associada a um projeto de CIM deve, desde logo, estabelecer um programa de reformulação da organização do trabalho na planta. Essencialmente, os responsáveis devem perceber que o foco de sua atenção não deve estar no trabalho direto em si, mas na mobilização da inteligência humana, coletiva, que faz desse trabalho algo produtivo. Cada caso é um caso; certamente várias plantas serão bem sucedidas partindo de programas de qualidade com envolvimento de trabalhadores; outras ganharão mais se, primeiro, rearrumarem sua estrutura de departamentos; talvez seja preciso, muitas vezes, recorrer ao "velho" estudo de tempos para levantamento de dados e reorganização do lay out da planta, para formação de grupos de trabalho. As possibilidades são inúmeras. É preciso que experiências concre- 
tas sejam levadas a cabo, para que se possa estabelecer uma metodologia para a ação; não há, no nosso conhecimento, solução pronta ou método elaborado para tal tipo de projeto.

Uma sugestăo inicial, entretanto, pode ser encontrada em Daniellou [5]. Para ele, a organização do trabalho deve se fundamentar na sustentação do "agir" - a ação com iniciativa - e não no "fazer" - o mero cumprimento do prescrito. Partindo de um olhar sistêmico, o projetista deve determinar quais os problemas perante os quais o coletivo de trabalho terá de agir, e ir delimitando os "espaços" de problemas a serem resolvidos, até que eles sejam tratáveis por uma equipe. A organização é então estruturada em torno destas equipes e dos mecanismos de retro-alimentação e de comunicação que permitirão a análise da origem dos problemas e a implantação de soluçð̄es. Daniellou [5] também chama atenção para a necessidade de se considerar os itinerários individuais na organização; em particular, destaca a necessidade de se permitir o afloramento de competências pessoais e o desenvolvimento permanente de quem se interessar por isto, dentro das equipes.

Parte complicada para implantação de uma organização deste tipo é o estabelecimento de um programa consistente de treinamento e formação de pessoal, acompanhado de políticas de recursos humanos de restrição ao máximo de turn over, e de atração de quadros capazes para a firma. Há aí uma superposição de problemas conjunturais, estruturais e subjetivos que tornam as decisões muito difíceis, mas não menos necessárias e relevantes.

Não há, portanto, uma proposta de projeto equivalente ao "estabelecer métodos e tempos - desenhar tarefas, funções e cargos - montar estrutura organizacional e desenhar controles' . Há apenas alguns princípios-guia, orientações gerais que indicam por onde começar. $\mathrm{E}$ o caminho a seguir não é único, até porque inseparável da estratégia global da firma. Mas já está colocada, hoje, a necessidade de construir a organização de trabalho de amanhã. Esta ação é inadiável, e precede $o$ investimento em capital fixo (cf. $[14,16]$ ).

\section{Referências Bibliográficas}

[1] ADLER, P.S. " Managing Flexible Automation" in California Management Review, Vol. XXX, No. 3, Primavera 1988.

[2] CAULliRAUX, H.M. Organização da Produção na Indústria de Informática Brasileira -- A Flexibilização do Trabalho Direto, apresentado no Seminário Internacional "Padrões Tecnológicos e Processo de Trabalho -- Comparações Internacionais" FEA/ USP, São Paulo, Maio de 1989.

[3] CORIAT, B. "Automatisation Programmable et Produits Differencies" in Anais do "Seminaire International Gerttd-Ames "Automatisation Programmable et Conditions d'Usage du Travail", Paris, 1987.

[4] --.----- L'Atelier et le Chronomètre. Christian Bourgois Ed., Paris, 1979.

[5] DANIELlOU, F. “'Ergonomie et Organization du Travail", cap. 10 in Cours B4: Ergonomie et Projets Industriels, LENT/CNAM, Paris, Mimeo, 1986/ 1987.

[6] DRÜCKER, P.F. Management: tasks, responsabilities, practices, Harper \& Row publs., New York, 1974.

[7] EMERY, F.E. “The Assembly Line - Its Logic and Our Future"' in DAVIS, L.E. e TAYLOR, J.C. Design of Jobs, Goodyear Publishing Company, Inc., 
2a ed., Santa Mônica, California, pp. 85-93, 1979.

[8] HAY, D.A. e MORRIS, D.J. Industrial Economics - Theory and Evidence, Cap. 2. Oxford University Press, 1979.

[9] HAYES, R.H., WHEELWRIGHT, S.C. e CLARK, K.B. Dynamic Manufacturing - Creating the Learning Organization. The Free Press, New York, 1988.

[10] KAPLINSKI, R. "The Economies of Small: Appropriate Technology in the Industrially Advanced Countries", Cap. 5, versão "draft" in Appropriate Technology: Theory and Praxis, preparado para Appropriate Technology International, 1989.

[11] POSSAS, M.L. Estruturas de Mercado em Oligopólio. Segunda Edição, ed. Hucitec, São Paulo, 1987.

[12] PROENÇA, A. e CAULliRAUX, H.M. Criação e Evolução de Empresas de Base Tecnológica - Avaliação Setorial - Indústria de Informática: Relatório Final. Convênio FINEP/OEA, Mimeo., 1989.

[13] -------- Desintegração Integrada: Um Novo Padrão de Organização Industrial. Mimeo, apresentado no Semi- nário "Padrões Tecnológicos e Políticas de Gestão: Processos de Trabalho na Indústria Brasileira", Depto. Sociologia, USP, Novembro de 1988. (Uma versão revista foi publicada no IEI/ UFRJ como texto para discussão No. 210).

[14] SEMLER, R. "Managing Without Managers" in Harvard Business Review, Setembro/Outubro, 1989.

[15] TALAYSUM, A.T.et alii. “Scale vs Scope: The Long-Run Economics of the CIM'FMS Factory" in SZELKE, E. e BROWNE, J. (eds.) Advances in Production Management Systems 85, Elsevier Science Publishers, 1986.

[16] TAUILE, J.R. Novos Padrões Tecnológicos, Competitividade Industrial e Bem Estar Social -- Perspectivas Brasileiras, IEI/UFRJ, Texto para Discussão No. 183, Janeiro de 1989.

[17] VELTZ, P. Informatique et "Intelligence de la Production". Mimeo, 1988.

[18] WOOD, S. "The Japanese Management Model" in Anais do IX ENEGEP, Vol. 3, UFRGS e UFSM, Porto Alegre, Setembro de 1989. 